ORIGINAL STUDY

\title{
Otologic symptomatology associated with the temporomandibular joint disorder
}

\author{
Gabriela Musat ${ }^{1,2}$, Laura Florina Neaga ${ }^{2}$, Raluca Enache ${ }^{3}$ \\ ${ }^{1}$ ENT\&HNS Department, "Sfanta Maria" Hospital, Bucharest, Romania \\ ${ }^{2}$ Faculty of Dental Medicine, "Carol Davila" University of Medicine and Pharmacy, Bucharest, Romania \\ ${ }^{3}$ ENT Sarafoleanu Medical Clinic, Bucharest, Romania
}

\begin{abstract}
BACKGROUND. Functional connection between the stomatognathic system and the acoustic-vestibular apparatus is approached with interest in topical studies, in an attempt to elucidate in depth the cause-effect relationship between pathology and symptom. The temporomandibular joint disorder may be accompanied by a series of otological symptoms such as otalgia, tinnitus and vertigo. For this reason, for a correct diagnosis, a complex clinical examination is required both on the acousticvestibular analyzer and on neighbouring structures.

MATERIAL AND METHODS. We conducted a clinical study, on a group of 97 patients diagnosed with temporomandibular joint disorder (TMJD) and treated for this pathology. All patients included in the study were evaluated by the dentist and the ENT specialist. The patients were treated at the dental clinic and then returned to the ENT clinic two months after completion of the treatment for re-examination, recording changes in otologic symptoms in order to obtain the results of the study.

RESULTS. Of the 97 patients with TMJD, 58 also associated otic symptomatology (otalgia - 74.13\%, tinnitus - 53.45\%, vertigo $-43.10 \%)$. The evaluation done two months after treatment of the temporomandibular joint disorder revealed a significant remission of otalgia (decrease in Mean VAS from 6.05 to 2.49), followed by vertigo (from 5.08 to 2.52) and by tinnitus (from 4.84 to 3.84 ). Important changes also occurred in the results of the vestibular assessments.

CONCLUSION. The most common otological symptom of patients with TMJD is auricular pain. Otalgia, tinnitus and vertigo can be improved by dental treatment of the temporomandibular dysfunction, auricular pain having the highest rate of remission.
\end{abstract}

KEYWORDS: temporomandibular joint disorder, otalgia, tinnitus, vertigo.

\section{INTRODUCTION}

Functional connection between the stomatognathic system and the acoustic-vestibular apparatus is mentioned from ancient times, being at the same time approached with interest in topical studies, in an attempt to elucidate in depth the cause-effect relationship between pathology and symptom.

The theoretical and practical knowledge of anatomy accumulated over the years represent an indisputable proof of the connection that exists between the two entities, but there is a continuing debate nowadays about the extent to which the pathology of the temporomandibular joint can generate otological symptoms and especially the limits within which the treatment for this disorder can influence the diminution of the manifestations of the acoustic-vestibular system.

Although symptoms such as otalgia, tinnitus, vertigo are commonly found in the ear pathology, ENT specialists are constantly confronted with situations where these phenomena are the clinical expression of certain disorders that go beyond the acoustic-vestibular analyzer. As the components of the dento-maxillary apparatus are, in many situations, cited as a source of the same symptomatology, the interdisciplinary collaboration between the ENT specialist and the dentist is essential in shaping a correct diagnosis and, implicitly, in focusing on an ideal treatment plan. 
Referring to the literature, one can say that the temporomandibular joint disorder (TMJD) is accompanied by a series of otological symptoms such as otalgia, tinnitus and vertigo ${ }^{1-8}$. For this reason, for a correct diagnosis, a complex clinical examination is required both on the acoustic-vestibular analyzer and on neighbouring structures.

This clinical study analyzes both the prevalence of otological symptoms in the temporomandibular joint disorder and the correlation between them, the extent to which the dental therapeutic intervention on the articular pathology may influence the manifestations of the acoustic-vestibular apparatus.

\section{MATERIAL AND METHODS}

We conducted a two-year clinical study, on a group of 97 patients diagnosed with temporomandibular joint disorder (TMJD) and treated for this pathology in the "Denta Plus" Dental Clinic from Bucharest. These patients were also examined in the ENT Department of the "Sfanta Maria" Clinical Hospital from Bucharest, both before and after treatment.

All patients have signed the informed consent, agreeing to be included in this study.

The results were analyzed based on the data from the initial ENT examination and subsequently by comparing clinical situations before starting the treatment and two months after its completion.

The patients who have been included in this study met the following criteria: adults, aged between 30 and 70 years (age average $=50$ years) who were diagnosed with temporomandibular joint disorder; patients who gave their consent to be included in the study.
Patients aged less than 30 years or older than 70 years were excluded from this study; patients with craniofacial abnormalities, cervical spine disorders, with diabetes, with clotting disorders, asthma, uncontrolled through medical treatment or untreated hypertension, with mental illness; patients who have undergone surgery at the level of the acoustic-vestibular systemin the past; pregnant women and non-compliant patients who did not offer their consent to be included in the study.

At the "Denta Plus" Dental clinic a diagnostic protocol has been developed for the temporomandibular joint disorder composed of a clinical examination and establishing the Helkimo clinical algo-dysfunction index value (Table 1). Over the course of 2 years, patients who achieved a Helkimo score of more than 10 were selected for the study, thus resulting in the 97 patients.

These patients were examined at the ENT Department of the "Sfanta Maria" Clinical Hospital in Bucharest in order to evaluate the otological symptoms. Besides the complete ENT clinical examination, we considered relevant to our study the following: detailed anamnesis accompanied by patient's completion of the Visual Analogue Scale questionnaire (VAS) for the evaluation of otological symptoms expressed through: otalgia, tinnitus, vertigo (Figure 1); audiological examination through liminal tonal audiometry with quantification of tinnitus intensity; evaluation of spontaneous nystagmus and of the provoked nystagmus through videonystagmography; evaluation of vestibulospinal reflexes, respectively of truncal deviations through the Romberg and Fukuda positional tests, as well as the quantitative assessment of balance in order to highlight the integrity of the vestibulospinal, the vestibulo-ocular axes and of vestibules through posturography.

\section{Table 1}

Table for identifying the Helkimo score ${ }^{9}$

\begin{tabular}{cccc}
\hline & & SEVERITY & \\
\hline SYMPTOM & NULL (ABSENT SYMPTOM) & MODERATE & GREAT \\
\cline { 2 - 4 } & O points & points & points \\
\hline Limitation of mandibular movements & $\begin{array}{c}\text { Maximum opening }>39 \mathrm{~mm} \\
\text { Maximum laterality }>6 \mathrm{~mm}\end{array}$ & $\begin{array}{c}\text { Maximum opening }=30-39 \mathrm{~mm} \\
\text { Maximum laterality }=4-6 \mathrm{~mm}\end{array}$ & $\begin{array}{c}\text { Maximum opening }<30 \mathrm{~mm} \\
\text { Maximum laterality }<4 \mathrm{~mm}\end{array}$ \\
\hline $\begin{array}{c}\text { Dysfunctional changes in the } \\
\text { temporomandibular joint }\end{array}$ & $\begin{array}{c}\text { Smooth motion, without lateral } \\
\text { deviations }\end{array}$ & $\begin{array}{c}\text { Joint noises and/or lateral } \\
\text { deviation } \geq 2 \mathrm{~mm}\end{array}$ & $\begin{array}{c}\text { The impossibility of making a movement } \\
\text { (e.g.: laterality) and/or subluxation }\end{array}$ \\
\hline $\begin{array}{c}\text { Pain caused by jaw movements } \\
\text { Pain caused by palpation of mandibular } \\
\text { mobilizing muscles }\end{array}$ & - & $\begin{array}{c}\text { After one mandibular } \\
\text { movement }\end{array}$ & After at least two mandibular movements \\
\hline $\begin{array}{c}\text { Pain caused by palpation of the } \\
\text { temporomandibular joint }\end{array}$ & - & $\begin{array}{c}\text { Sensitivity to palpation in 1-3 } \\
\text { points }\end{array}$ & Sensitivity to palpation in at least 4 points \\
\hline
\end{tabular}




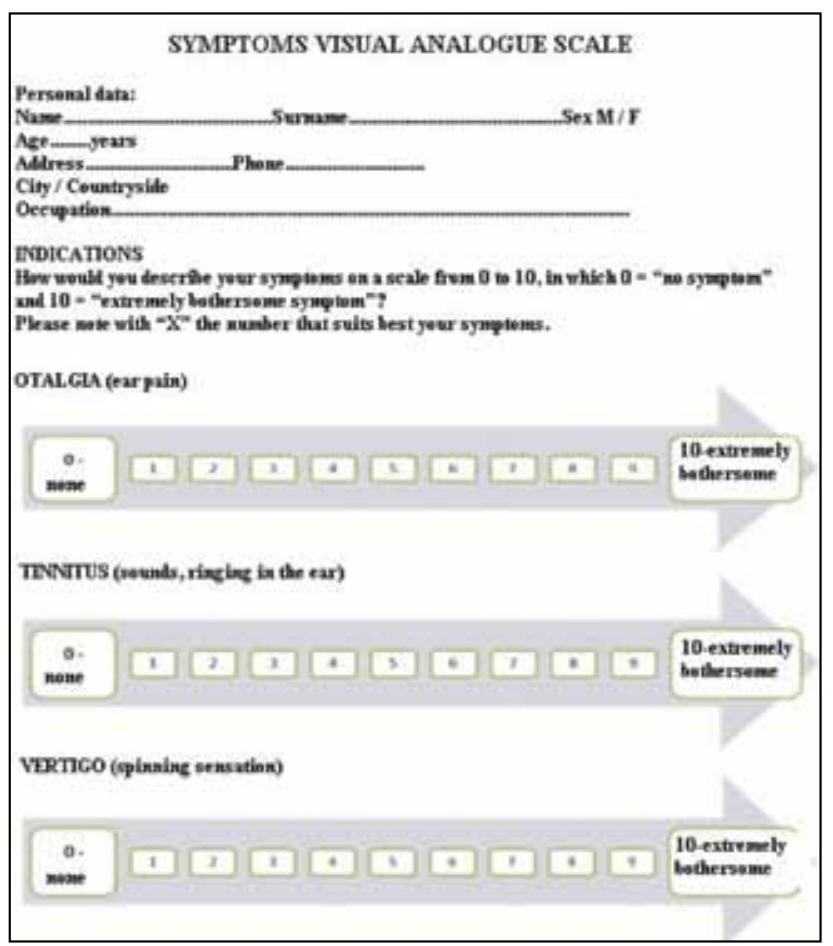

Figure 1 Symptoms Visual Analogue Scale

The patients were treated at the dental clinic, each for a variable period of time appropriate to the clinical situation and then returned to the ENT clinic two months after completion of the treatment for re-examination, recording the changes in otologic symptoms in order to obtain the results of the study. The therapeutic means aiming to improve temporomandibular joint disorders consisted in: occlusal splint, selective grinding with removal of the enamel from certain areas considered occlusal obstacles, prosthetic or orthodontic treatment by correcting dental malformations, functional re-education.

\section{RESULTS}

Of the 97 patients (women:men $=2.23: 1$ ) with temporomandibular joint disorder (TMJD) included in the study, a subgroup of 58 patients $(59.79 \%)$ also had otic symptomatology. The 58 patients presented various symptoms, the most common symptom being otalgia, which was detected in 43 patients (Figure 2), therefore a percentage of $74.13 \%$.

Vertigo was the symptom found in the smallest proportion with a percentage of $43.10 \%$ of the total (25 patients), but, overall, it is actually about half of the patients in the subgroup, which is why we will give it due consideration.

Tinnitus ranks second in the frequency ranking with a number of 31 patients, representing a percentage of $53.45 \%$ of the total.

According to the statistical analysis, Figure 3 shows that otalgia intensity measured by VAS scores has obtained a mean value of 6.05 as per the data from the initial ENT examination and a mean value of 2.49 as per the data recorded after the treatment of TMJD, resulting in a decrease in the mean value by 3.56 units.

In Figure 4 one can observe the VAS scores for otalgia before and after treatment of the temporomandibular disorder. Note that for the scores recorded at the initial ENT examination we used the code "Otalgia 1 ", and for the scores registered after dental treatment, the code "Otalgia 2". It is noteworthy that initially, of the group of 58 patients, 15 chose the score " 0 " for otalgia, thus 15 out of 58 patients did not have this symptom, while at the second examination, the number of patients who mentioned the lack of this symptom increased to 28. Moreover, another significant increase in the number of patients is among those who rated otalgia with the score "2": initially, there were 3 patients, and after the treatment of TMJD, 10 patients. For the scores " 3 " and " 4 ", the increase in the number of patients is not as extensive, but we consider it a notable difference. Regarding the score "1", the number of patients remained the same. The decrease in the number of patients who chose the score " 5 ", therefore with higher otalgia intensity, is also relevant.

Overall, otological symptomatology expressed by otalgia revealed remissions after the treatment of the temporomandibular joint disorder, the chart showing a single stagnation for the score " 1 ", no decrease in

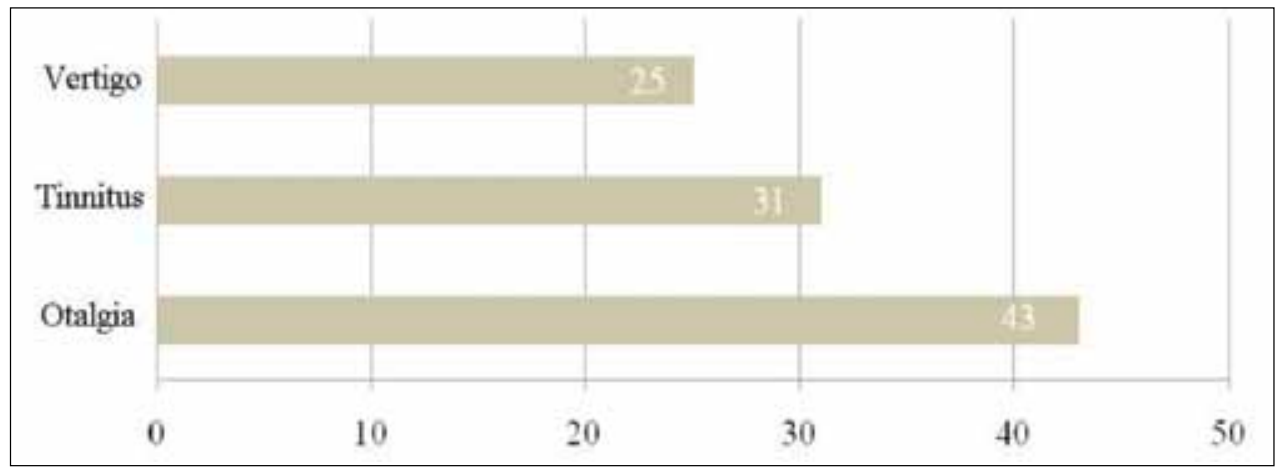

Figure 2 Distribution of patients according to symptomatology, according to VAS. 


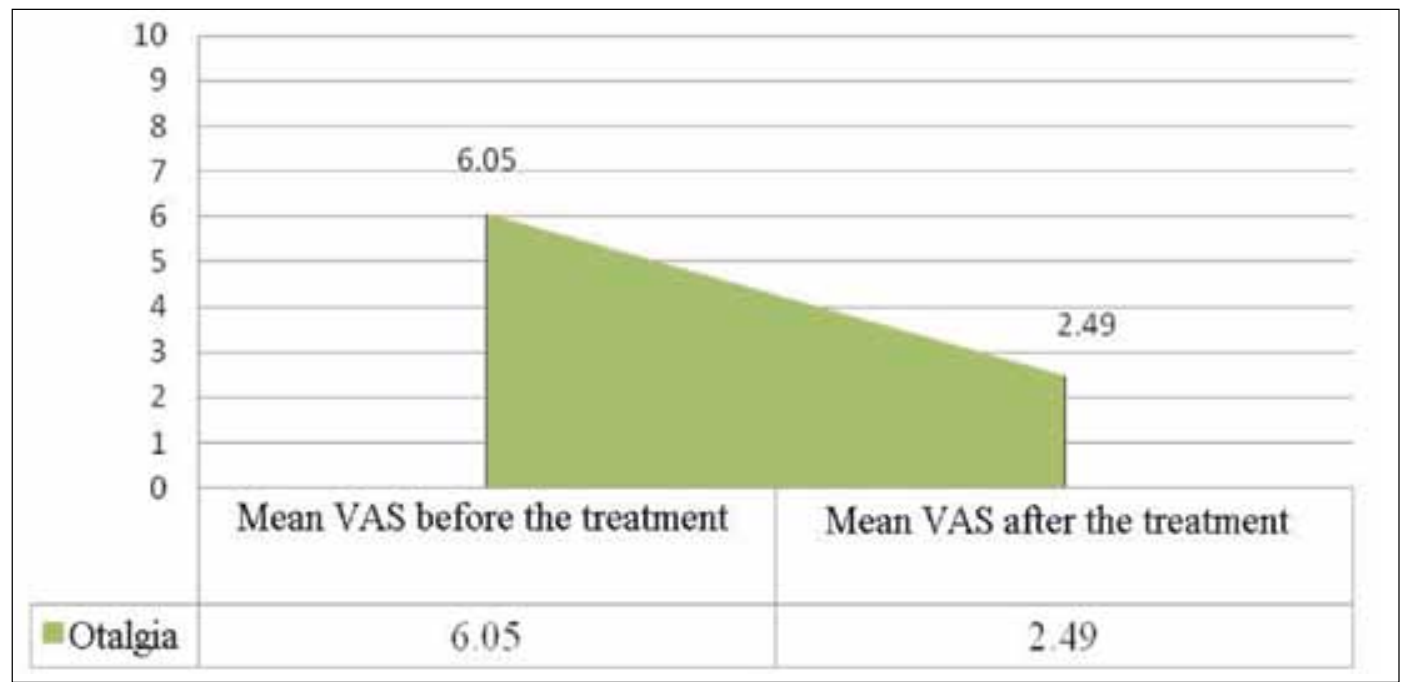

Figure 3 Evolution of the VAS mean value for otalgia.

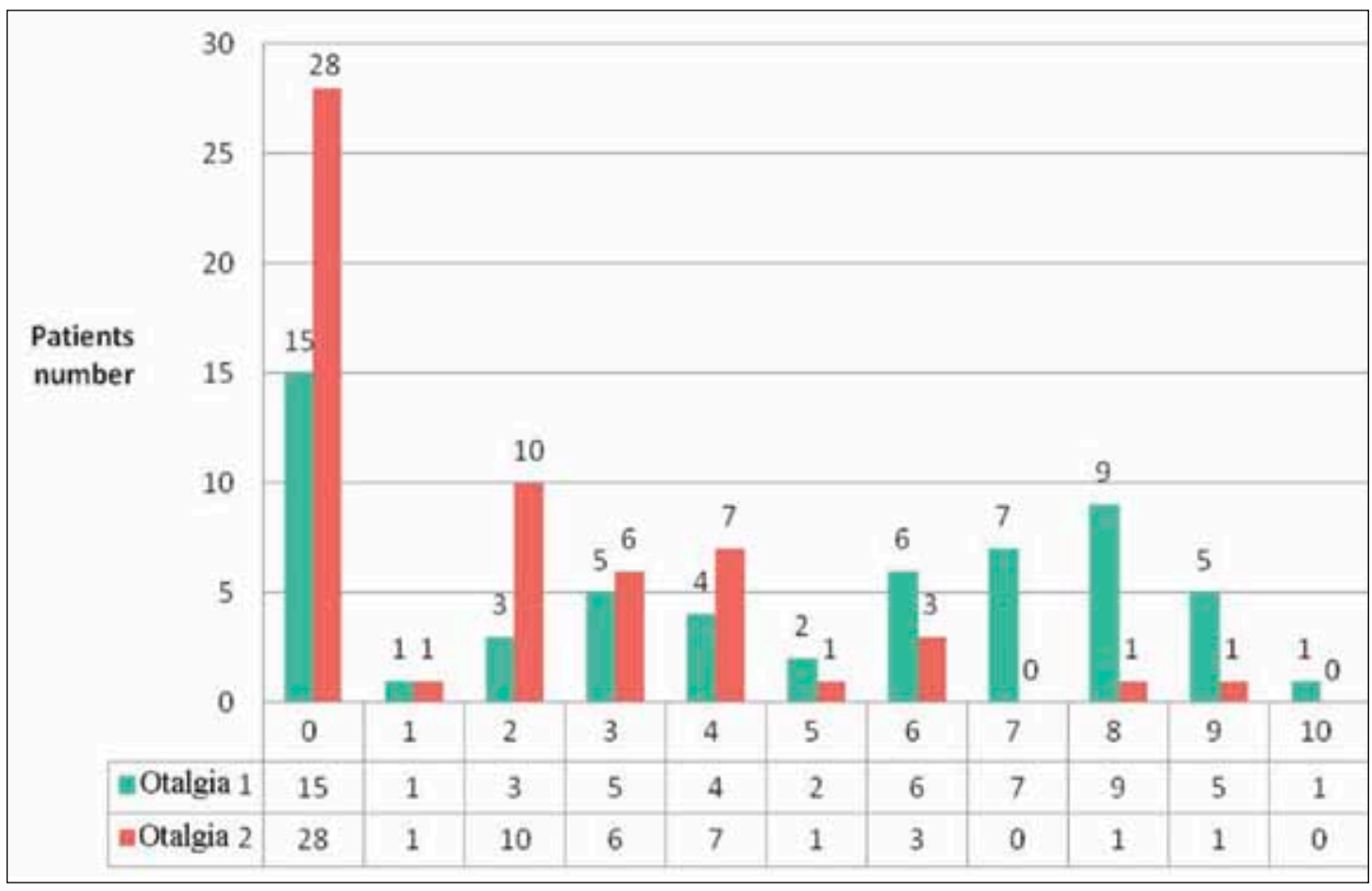

Figure 4 Distribution of patients according to the VAS value for otalgia, before and after treatment of the temporomandibular dysfunction.

the extremes of small scores, that is, in low intensities, and no increase in the extremes of high scores, that is, in high intensities.

With regard to the tinnitus, the intensity calculated using VAS scores has achieved a mean value of 4.84 as per the data recorded initially and a mean value of 3.84 as per the data recorded after the treatment of TMJD, resulting in a decrease in the mean value by 1 unit (Figure 5).

Observing comparatively the VAS scores for tinnitus before ("Tinnitus 1") and after treatment of the temporomandibular disorder ("Tinnitus 2") it is notewor- thy that there was no change in patients who initially recorded the intensity of tinnitus with the score " 0 ", namely in those who mentioned the lack of this symptom: 27 patients without tinnitus at the initial examination and still 27 patients after treatment (Figure 6). This highlights the lack of total remission of this symptom after treatment, regardless of intensity.

On the other hand, there is an increase in the number of patients with small scores ("1", "2", "3", "4"), namely of slow intensities and a decrease in the number of patients with high scores ("6", “7”, " 8 ", "9"), namely of high intensities. 


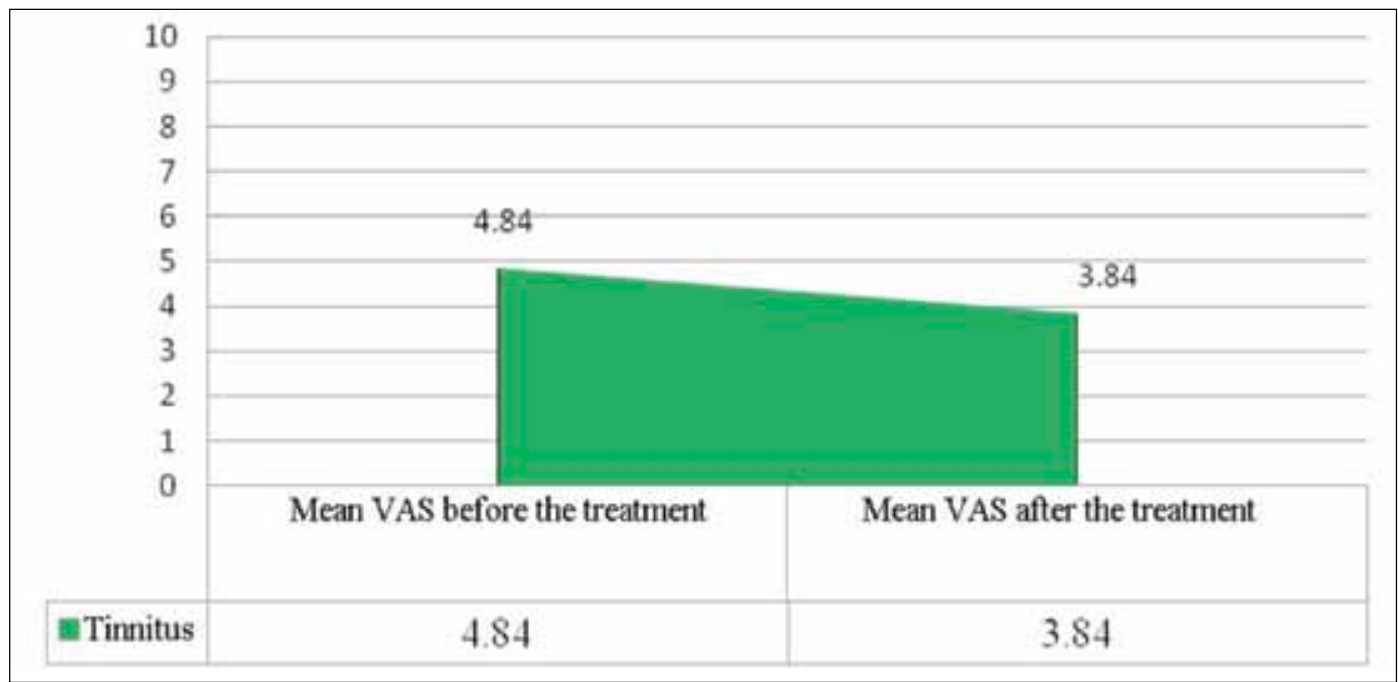

Figure 5 Evolution of the VAS mean value for tinnitus.

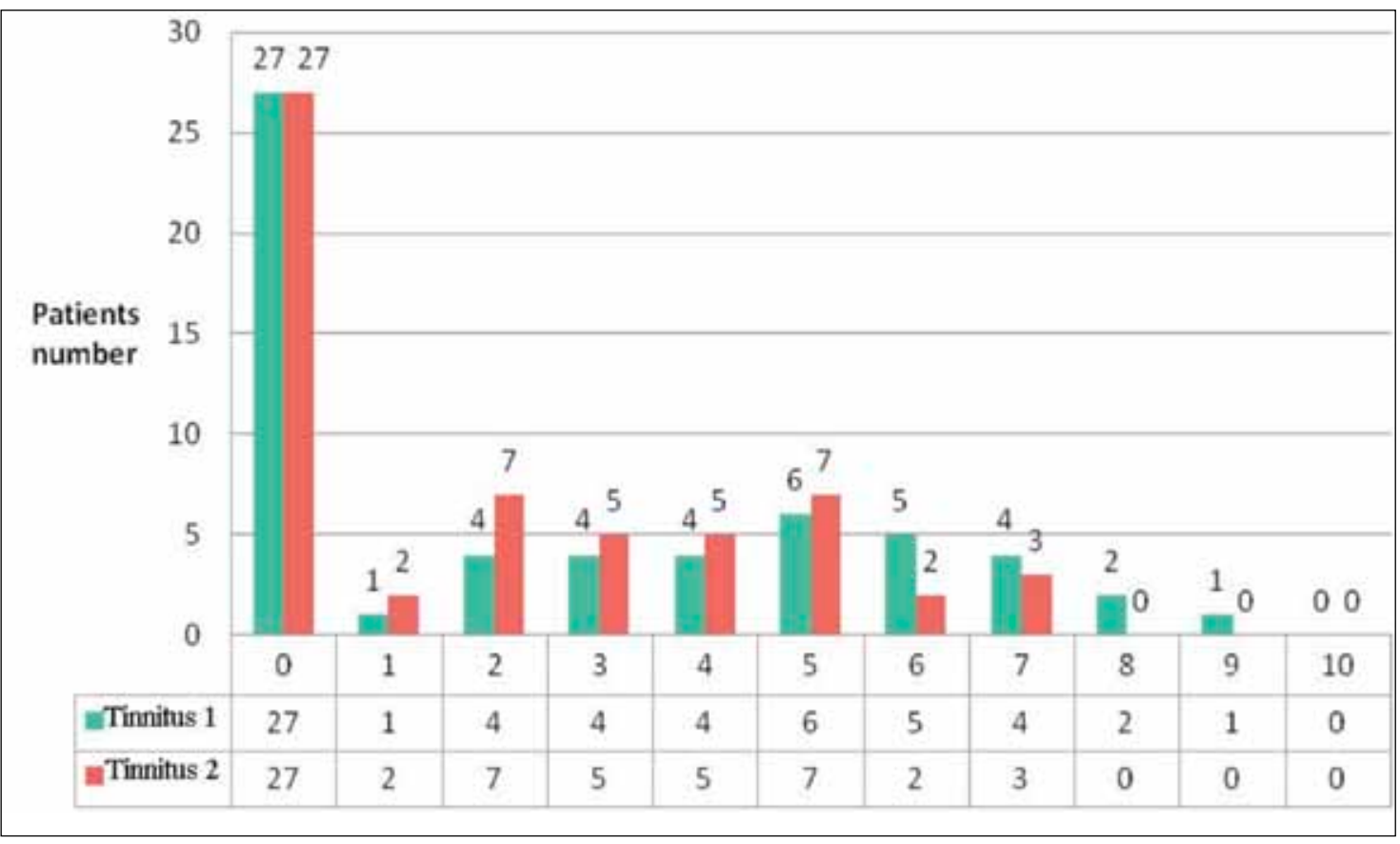

Figure 6 Distribution of patients according to the VAS value for tinnitus, before and after treatment of the temporomandibular dysfunction.

For the third symptom analyzed in our study, the intensity measured by VAS scores obtained a mean value of 5.08 as per the data recorded at the initial examination and a mean value of 2.52 as per the data recorded after the treatment of TMJD (Figure 7). This resulted in a decrease in the mean value by 2.56 units.

Comparatively, VAS scores for vertigo before ("Vertigo 1") and after treatment of the temporomandibular disorder ("Vertigo 2") show an increase in the number of patients who marked with "0" the VAS score attributed to "Vertigo" after treatment of TMJD, from 33 patients to 37 patients. Moreover, it is highlighted the decrease to 0 in patients who marked the vertigo intensity with the extreme values "8", respectively "9" (Figure 8).
Therefore, the symptom that benefited from the highest rate of remission after treatment of the temporomandibular joint disorder was otalgia (Figure 9).

Regarding the list of ENT procedures, tests and examination samples, pathological changes have been observed after performing the audiometric and vestibular evaluations (Table 2).

The tests that showed changes at the initial examination were repeated two months after completion of the treatment for the temporomandibular joint dysfunction. The obtained results are represented comparatively in Figure 10.

Following the audiometric testing, 31 patients were diagnosed with sensorineural hearing loss with lowering the threshold on high frequencies. We did not 


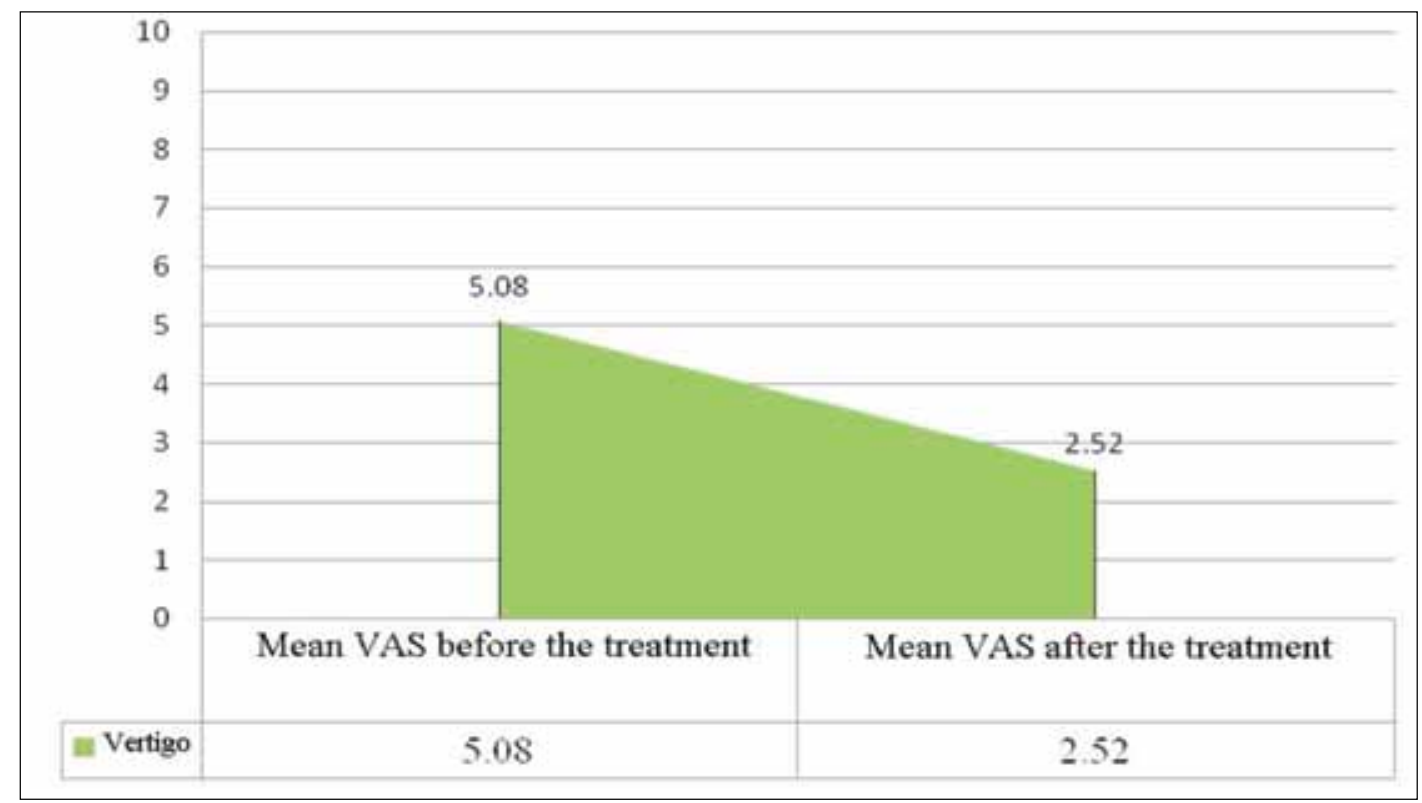

Figure 7 Evolution of the VAS mean value for vertigo.

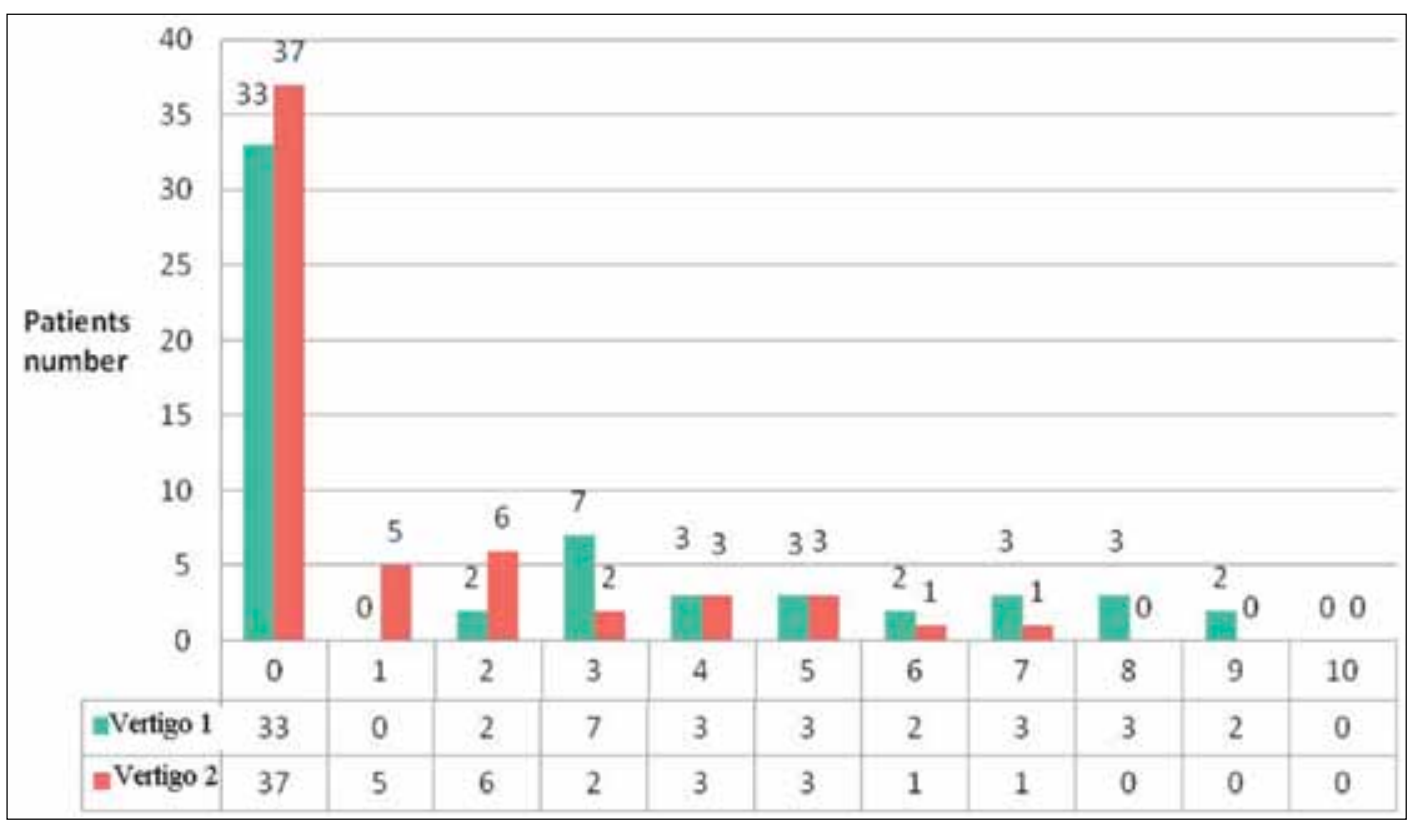

Figure 8 Distribution of patients according to the VAS value for vertigo, before and after treatment of the temporomandibular dysfunction.

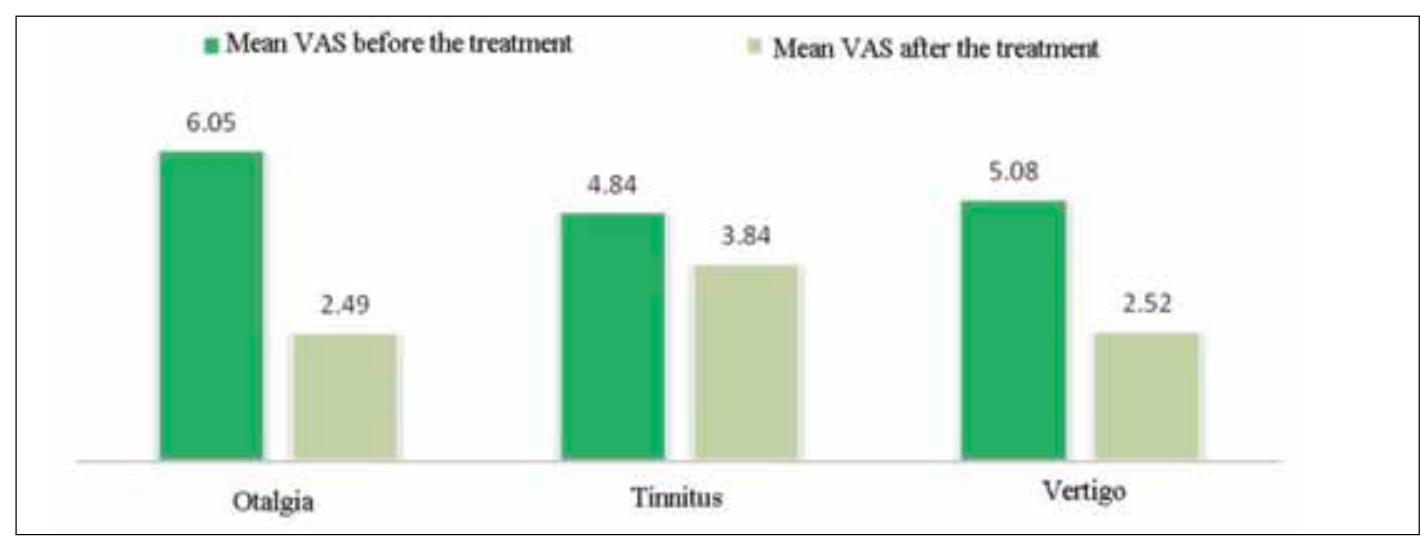

Figure 9 Distribution of otological symptomatology according to the mean VAS score, before and after treatment of TMJD. 
Table 2

Distribution of patients with pathological changes at the ENT clinical examination

\begin{tabular}{ccc}
\hline & $\begin{array}{c}\text { Pathological } \\
\text { changes (Yes/No) }\end{array}$ & $\begin{array}{c}\text { Number of patients } \\
\text { with pathological } \\
\text { changes }\end{array}$ \\
\hline Otoscopy & No & 0 \\
\hline Anterior rhinoscopy & No & 0 \\
\hline Posterior rhinoscopy & No & 0 \\
\hline Bucopharyngoscopy & No & 0 \\
\hline Indirect laryngoscopy & No & 0 \\
\hline Audiogram & Yes & $\mathbf{3 1}$ \\
\hline Spontaneous & Yes & $\mathbf{5}$ \\
\hline nystagmus & No & 0 \\
\hline HIT test & Yes & $\mathbf{1 0}$ \\
\hline HST test & No & 0 \\
\hline Dix-Hallpike test & No & 0 \\
\hline Roll test & Yes & $\mathbf{5}$ \\
\hline Romberg test & Yes & $\mathbf{5}$ \\
\hline Fukuda test & Yes & $\mathbf{8}$ \\
\hline Posturography & & \\
\hline & & \\
\hline & &
\end{tabular}

consider these changes relevant to our study, as they fall within the pathology emerging under the stigma of advanced age. The majority of $83.87 \%$ was made up of patients aged between 61 and 70 years, being 26 in number, and the remaining of $16.13 \%$ was made up of patients aged between 51 and 60 years. Therefore, there was no patient with sensorineural hearing loss within the age range 30-50 years, and those with this pathology fell within the range 51- 70 years.
Analyzing the chart, we note that of the 5 patients with a positive response at Romberg and Fukuda tests, two of them received a negative response to these tests at the second examination, the spontaneous nystagmus being also cancelled. Regarding the HST tests, the results were favourable, since the number of patients responding positively to this assessment dropped from 10 to 4 . When repeating the quantitative assessment of balance, posturography revealed 4 cases of improvement in the vestibular score of the total of 8 patients with posturography changes (Figure 11).

\section{DISCUSSIONS}

The temporomandibular joint (TMJ) is the most advanced articulation of the human body, showing a dual mobility. Moreover, it is the only mobile joint in the skull. It indirectly, but continuously, receives occlusal pressures, which is why any change in the occlusal field (edentations, bruxism, dental wear) modifies the morphology of TMJ components by remodelling.

It has a common embryological origin with other cranio-facial structures, but its development and evolution have a particular character, being remarked by a high degree of biomechanical and kinetic complexity, justifying the symptomatology of temporomandibular disorders ${ }^{10,11}$.

The temporomandibular disorder is also found in the literature under the name of "painful myofascial syndrome" or "occlusal-articular algo-dysfunctional syndrome". It is a common disorder showing multiple symptoms, even disabling in some cases. In terms of symptoms, the temporomandibular disorder can man-

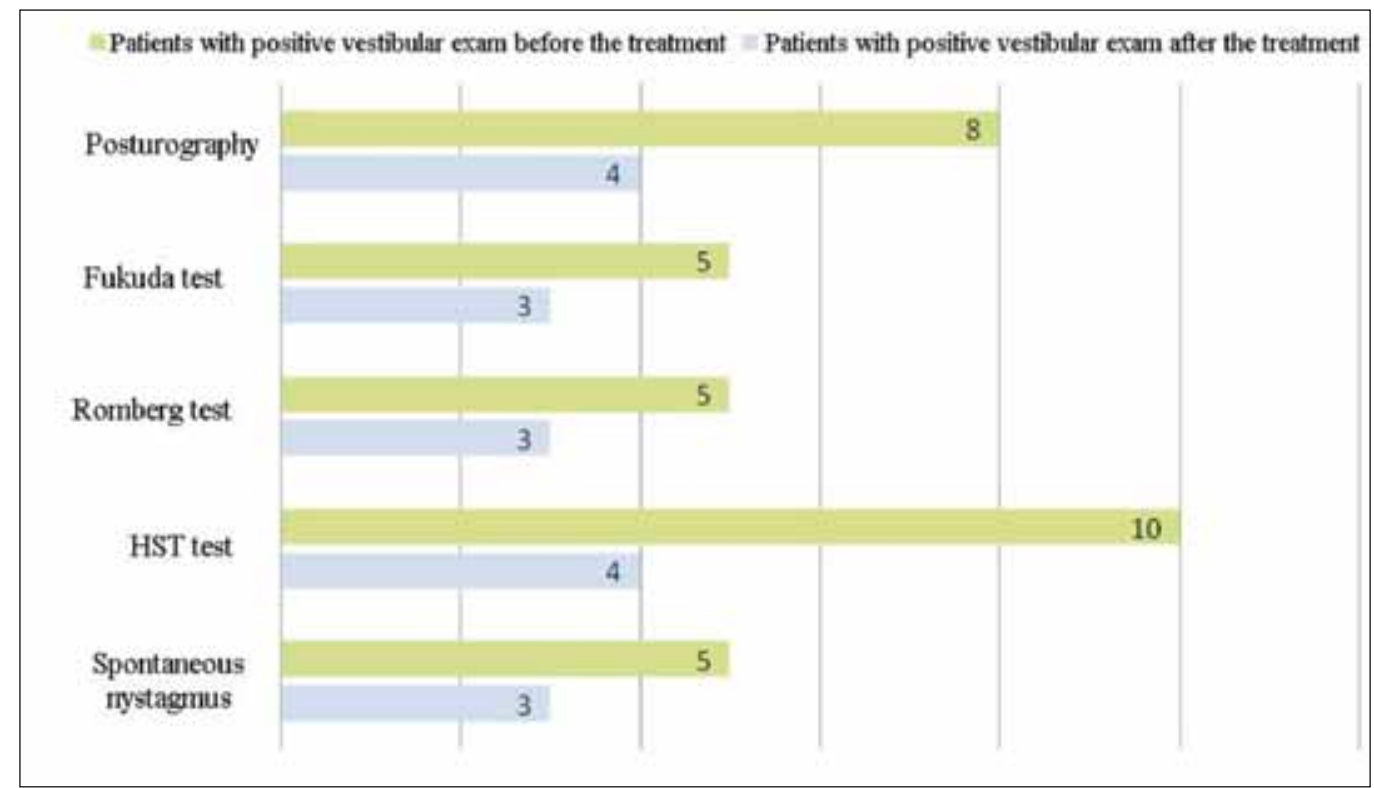

Figure 10 Distribution of patients according to the test results of the vestibular exam, before and after treatment of TMJD. 


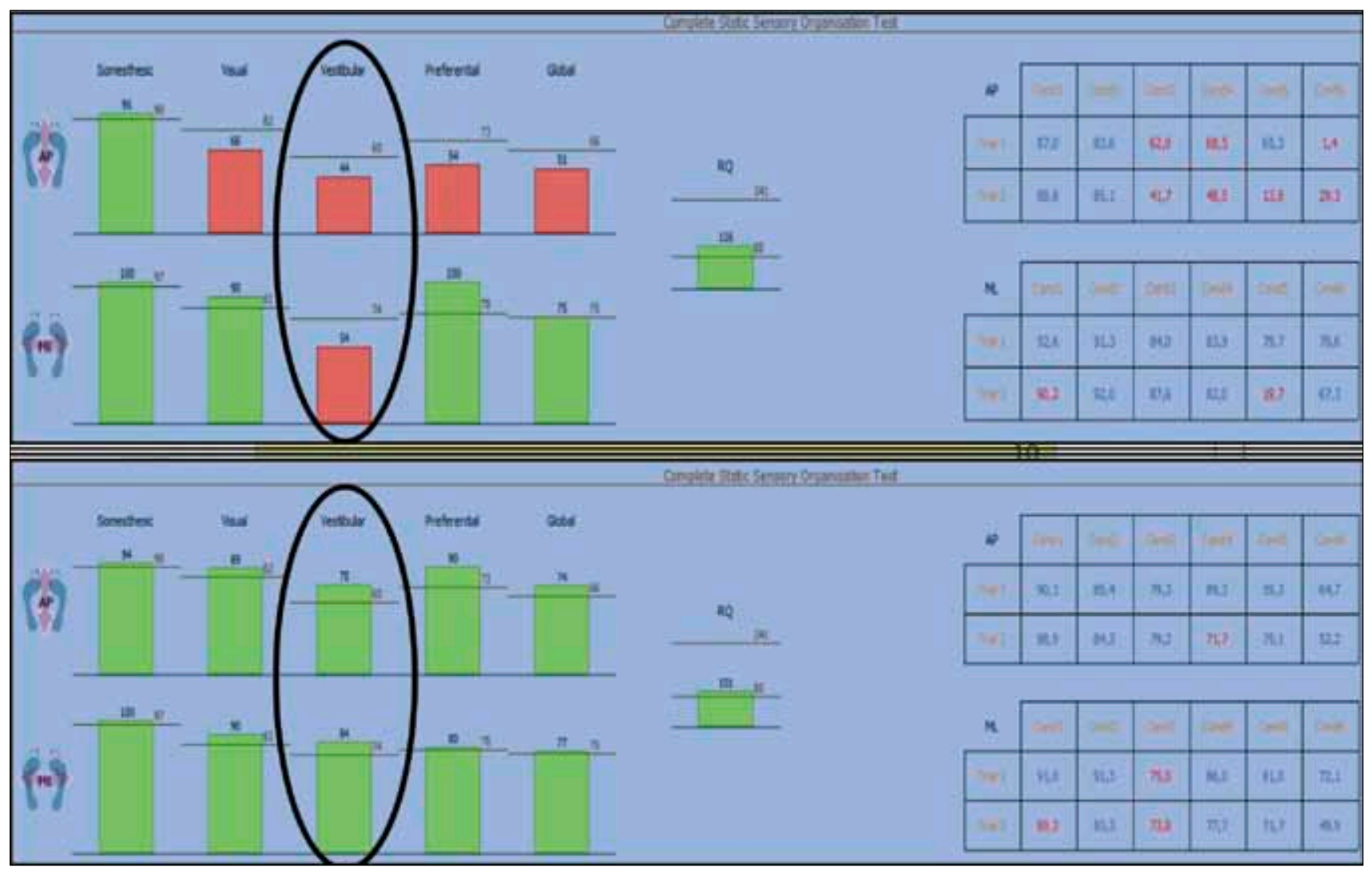

Figure 11 Vestibular score improvement in posturography.

ifest at the level of teeth, muscles or joints. Symptomatology at the dental level occurs through occlusal overload and is manifested by dental mobility or pathological abrasion. Symptomatology from the muscular level is the one that alarms the patient most because of the discomfort that varies from mild discomfort to high intensity pain. Pain can be manifested in the affected muscle area or may radiate to the preauricular, nasal, orbital, occipital, mastoid, supraclavicular level, another reason requiring a differential diagnosis. Painful symptoms are predominantly unilateral, can be relieved by rest or heat and may often simulate phenomena of maxillary sinusitis or otitis. Moreover, the association with otic phenomena such as tiredness, hearing loss, balance disorder is also very important. Symptomatology at the articular level appears the latest and is manifested when mobilizing the mandible, especially when masticating sticky or hard foods, unlike muscular pain that can be constantly present.

Regarding the onset of otalgia, tinnitus and vertigo in temporomandibular joint disorders, there are several hypotheses attempting to explain the etiology of these symptoms. One of these is based on the possibility of mechanical transmission of forces from the temporomandibular joint to the middle ear, via the discomalleolar ligament ${ }^{6,12}$. In their study, Ren and Isberg show a significant correlation between the unilateral presence of tinnitus and the movement of the condyle from the temporomandibular joint ${ }^{12}$. Another theory invokes the irritating potential of the mandibular condyle on the auriculotemporal nerve $e^{6,13}$. Frequent mention is also made of the common innervation of the mandibular muscles and the tensor tympani muscle ${ }^{14,15}$.

In 1920, Monson reported a case of sudden hearing loss due to a pathological location of the mandibular condyle $^{16}$. Five years later, Decker described a series of cases of hearing impairment in patients with deep occlusion or posterior localization of the mandibular condyle in the glenoid fossa ${ }^{13}$.

In 1933, Goodfriend noted the link between the incidence of tinnitus and the stomatognathic system dysfunction, a theme also approached by Costen in $1934^{1,14}$. Other authors consider there is an increase in tinnitus intensity with up to $75 \%$ during voluntary movements of the temporomandibular joint ${ }^{17,18}$.

Masseter and ear muscles have a common embryological origin, the first pharyngeal arch being mentioned in studies as a factor contributing to this correlation between otological symptoms and TMJ pathology $y^{10,11}$. Muscle involvement in the occurrence of otic symptomatology in patients with TMJ pathology is supported by many other studies ${ }^{6,19-21}$.

Also, edentation, pathological attrition or occlusal trauma may be factors contributing to a posterior posi- 
tion of the mandibular condyle, causing compression of the tympanic artery and vein. This mechanism may lead to hearing loss due to inappropriate irrigation of the middle ear. Simultaneously, the compression of the tympanic nerve by the mandibular condyle determines the contraction of the stapedius muscle of the stapes through a reflex mechanism transmitted through the facial nerve. The auriculotemporal nerve is also affected through this compression mechanism, causing the contraction of the tensor tympani muscle and generating the appearance of tinnitus or hearing loss ${ }^{22-24}$.

Kamerer and Gray have demonstrated in their studies that the tensor tympani muscle would respond to external stimuli, such as mastication, swallowing or movements performed by facial muscles ${ }^{25,26}$.

The presence of non-otologic symptomatology in patients with temporomandibular arthritis has also been demonstrated by Lam et al.; they have demonstrated a presence of tinnitus in these patients comprised between 3.5 and $42 \%$, far greater than the presence of this symptom in the general population ${ }^{27}$. In our study, the frequency of tinnitus was $53.45 \%$.

Cooper revealed an important prevalence of vestibular symptoms in patients with temporomandibular joint disorders - dizziness present in a proportion of $40-70 \%$ and vertigo in a proportion of $5-40 \%{ }^{28}$. $43.10 \%$ of patients included in the present study have experienced vertigo as the associated symptom of a TMJ disorder.

Otalgia has been shown to be the most common otic symptom associated with the temporomandibular joint disorders. Thus, Kasnisci et al. have demonstrated an incidence of otalgia of $66.7 \%$, Lam et al. of $32 \%$, while Tuz et al. of $57.2 \%{ }^{27,29,30}$. In the study presented in this article, the results correlate with those in the literature, otalgia representing $74.13 \%$ of the symptoms.

The relationship between otic symptomatology and the temporomandibular joint disorder is also supported by the fact that the treatment of the latter results in a significant improvement in otic symptoms, even to their disappearance ${ }^{31-35}$. This aspect has been also demonstrated by the present study.

\section{CONCLUSIONS}

1. Otic symptomatology is common in patients with temporomandibular joint disorder.

2. The most common otologic symptom of patients with temporomandibular joint disorder is auricular pain.

3. Otalgia, tinnitus and vertigo can be improved by dental treatment of the temporomandibular disorder, auricular pain enjoying the highest rate of remission.
4. The results of posturography can also be positively influenced by the treatment of the TMJ disorder, resulting in an improved vestibular score.

5. Taking into account the need for complex clinical examination both of the acoustic-vestibular analyzer and of neighbouring structures for a correct and implicit diagnosis, for orientation towards an ideal treatment plan, the interdisciplinary collaboration between the ENT physician and the dentist is essential.

Conflict of interest: The authors have no conflict of interest.

Contribution of authors: All authors have equally contributed to this work.

\section{REFERENCES}

1. Goodfriend DJ. Symptomatology and treatment of abnormalities of the mandibular articulation. Dent Cosmos. 1933;75:844,947,1106.

2. Principato JJ, Barwell DR. Biofeedback training and relaxation exercises for treatment of temoporomandibular joint dysfunction. Otolaryngology. 1978;86(5):ORL-766-9.

3. Brookes GB, Maw AR, Coleman MJ. "Costen's syndrome" - correlation or coincidence: a review of 45 patients with temporomandibular joint dysfunction, otalgia and other aural symptoms. Clin Otolaryngol Allied Sci. 1980;5(1):23-36.

4. Chole RA, Parker WS. Tinnitus and vertigo in patients with temporomandibular disorders. Arch Otolaryngol Head Neck Surg. 1992;118(8):817-21.

5. Felicio CM, Faria TG, Silva MA, Aquino AM, Junqueira CA. Temporomandibular disorders: relationship between otologic and orofacial symptoms. Rev Bras Otorrinolaringol. 2004;70(6):786-93. http:// dx.doi.org/10.1590/S0034-72992004000600014.

6. Ramirez Aristeguieta LM, Sandoval Ortiz GP, Ballesteros LE. Theories on otic symptoms in temporomandibular disorders: past and present. Int J Morphol. [Internet]. 2005;23(2):141-56. Available from: http://www.scielo.cl/scielo. php?script=sci_arttext\&pid=S0717-95022005000200009\&lng=es. http:// dx.doi.org/10.4067/S0717-95022005000200009.

7. Buraa MF, Alazzawi HS. The relationship among otic clinical findings and temporomandibular joint disorders population. The Iraqi Postgraduate medical Journal. 2013;12(4):546-50.

8. Cox KW. Temporomandibular disorders and more aural symptoms. Arch Otolaryngol Head Neck Surg. 2008;134(4):389-93.

9. Ionita S, Petre A. Ocluzia dentara. Editura Didactica si Pedagogica, R.A.Bucuresti; 1999, p. 160-237.

10. Whyte JR, Gonzalez L, Cisneros AI, Yus C, Torres A, Sarrat R. Fetal development of the human tympanic ossicular chain articulations. Cells Tissues Organs. 2002;171(4):241-9.

11. Rodriguez Vazquez JF, Merida Velasco JB, Jimenez Collad J. A study of the os goniale in man. Acta Anat (Basel). 1991;142(2):188-92.

12. Ren YF, Isberg A. Tinnitus in patients with temporomandibular joint internal derangement. Cranio. 1995;13(2):75-80.

13. Decker JD. Traumatic deafness as a result of retrusion of the condyles of the mandible. Ann Otol Rhinol Laryngol. 1925;34(2):519.

14. Costen J. A symdrome of ear and sinus symptoms dependent upon disturbed function of the temporomandibular joint. 1924. Ann Otol Rhinol Laryngol. 1934;106(10 Pt 1):805-19. 
15. Fanali S, Cerri A. The otoneurological and dental picture of Costen's pain - dysfunction syndrome. Minerva Stomatol. 1993;42(1-2):37-43.

16. Monson GS. Some important factors which influence occlusion. The Journal of the American Dental Association. 1922;9(6):498-503. https:// doi.org/10.14219/jada.archive.1922.0144.

17. Lockwood AH, Salvi RJ, Coad ML, Towsley ML, Wack DS, Murphy BW. The functional neuroanatomy of tinnitus: evidence of limbic system links and neural plasticity. Neurology. 1998;50(1):114-20.

18. Vergara RM. Audicion y sordera. Lerner Ltda., DRG 2000 Ltda. Colombia; 1996, cap 9 .

19. Campbell CD, Loft GH, Davis H, Hart DL. TMJsymptoms and referred pain patterns. I Prosthet Dent. 1982;47(4):430-3.

20. Myrhaug $\mathrm{H}$. The incidence of the ear symptoms in cases of malocclusion and temporo-mandibular joint disturbances. Br J Oral Surg. 1964;2(1):28-32.

21. Green CS. The etiology of temporomandibular joint disorders: implications for treatment. J Orofac Pain. 2001;15(2):93-105; discussion 106-16.

22. Gola R, Chossegros C, Orthlieb JD, Lepetre C, Ulmer E. Otologic manifestations of the pain dysfunction syndrome of the stomatognathic system. Rev Stomatol Chir Maxillofac. 1992;93(4):224-30.

23. Kaygusuz I, Karlidag T, Keles E, Yalcin S, Yildiz M, Alpay HC. Ear symptoms accompanying temporomandibular joint diseases. Kulak Burum Bogaz Ihtis Derg. 2006;16(5):205-8.

24. Lewandowski L, Wybieralski J. Odontogenic and stomatogenic otalgia in diseases the teeth, mouth and jaws. Otolaryngol Pol. 1982;36:301-4.

25. Gray LP. The relationship between the "superior constrictor swallow" clicking of the ears and ear disease. J Laryngol Otol. 1983;97(12):1121-8. DOI: $10.1017 /$ S0022215100096080.
26. Kamerer DB. Electromyographic correlation of tensor tympani and tensor veli palatine muscles in man. Laryngoscope. 1978;88(4):651-62.

27. Lam DK, Lawrence HP, Tenenbaum HC. Aural symptoms in temporomandiular joint disorder patients attending a orofacial pain unit. J Orofac Pain. 2001;15(2):146-57.

28. Cooper BC, Alleva M, Cooper DL, Lucente FE. Miofascial pain dysfunction: analysis of 476 patients. Laryngoscope. 1986;96(10):1099-106.

29. Kasnisci R, Onder E, Tuz H. Prevalence of otologic complaints in temporomandibular diroders patients. In J Oral \& Maxillofacial Surgery. 1999;28(1):101-2.

30. Tuz HH, Onder EM, Kasnisci RS. Prevalece of otologic complaints in patients with temporomandibular disorders. Am J Orthod Dentofacial Orthop. 2003;123(6):620-3.

31. Wright EF, Syms CA 3rd, Bifano SL. Tinnitus, dizziness, and nonotologic otalgia improvement through temporomandibular disorders therapy. Mil Med. 2000;165(10):733-6.

32. Wright EF, Bifano SL. Tinnits improvement through TMD therapy. J Am Dent Assoc. 1997;128(10):1424-32.

33. Torii K, Chiwara I. Occlusal management for a patient with aural symptoms of unknown etiology: a case report. J Med Case Rep. 2007;1:85. DOI 10.1186/1752-1947-1-85.

34. Badel T, Panduric J, Marotti M, Kocijan L. Temporomandibular joint disorder in an otalgia patient. Acta Stomatol Croat. 2006;40(2):175-81.

35. Al-Habahbeh R, Al-Zioud W, Al-Khtoum N. Prevalence of otalgia in patients with temporomandibular disorders and response to treatment. Middle East Journal of Family Medicine [Internet]. 2005;3(4). Available from: http://wwwmejfm.com/journal/Sep05/Prevalence of_Otalgia.htm 